\title{
Alcohol Production and Consumption in Contemporary Europe: Identity, Practice and Power Through Wine
}

\author{
Kate Ferris and Stella Moss
}

School of History, University of St Andrews, St Katharine's Lodge, The Scores, St Andrews, KY16 9BA, UK kf50@st-andrews.ac.uk and Department of History, Royal Holloway, University of London, Egham, Surrey, TW20 0EX, UK Stella.Moss@rhul.ac.uk

Drinking - producing, procuring, distributing and consuming alcoholic drinks - is central to the human experience. Drinking is a social and cultural practice, embedded in both everyday and extraordinary activities and rituals connected to our leisure, working, festive and commemorative time. Alcohol, its production, regulation, consumption, associated practices, material accoutrements and spaces are agents and vectors that also have clear political and economic dimensions. As such, alcohol and drinking have occupied a crucial place in shaping and governing interactions between states and their citizens and, therefore, in the articulation of political power and agency. Drinking is also intimately bound up with complex and changing processes of the formation and expression of identities, individual and collective, and of socio-cultural practices, nationally, but also locally, regionally and transnationally.

This collection expands our understanding of wine in twentieth-century Europe and, more broadly, seeks to intervene in scholarly discussion of alcohol across a range of fronts. The production, consumption, regulation and imagination of wine are all explored, not only for what they reveal about the place of alcohol - as a beverage, intoxicating substance and commodity that plays a central role in human practices, interactions and relationships - in twentieth-century European history, but also for what these reveal more broadly about the value of using alcohol as a lens through which to consider structures, experiences, influences and discourses in modern states and society. As historian Thomas Brennan has contended, 'we can learn a great deal about society through the prism of a wine glass'.

Interest in alcohol has been growing among historians in recent years. ${ }^{2}$ Much of this interest is consciously interdisciplinary, framed as part of the growing 'drinking studies' field, which sees historians' interests intersect with those of sociologists, anthropologists, criminologists and political scientists, economists, legal scholars, social and behavioural psychologists, public health academics and other scientists. One strand of historical work centred on popular drinking habits has underlined the (ab) use of alcohol in the context of social dislocation, with habitual drunkenness posited as a response to material deprivation and an expression of anomie. ${ }^{3}$ Linked to this, historians have also focused on attempts to regulate drinking, either through legislative means or via the inculcation of social norms promoting sobriety on grounds of health and welfare, social propriety and/or religious belief. ${ }^{4}$

\footnotetext{
1 Thomas Brennan 'Towards the Cultural History of Alcohol in France', Journal of Social History, 23, 1 (1989), 85.

2 For examples of the developing scholarship from a historical discipline/perspective see, for example: Mack P. Holt, ed., Alcohol: A Social and Cultural History (Oxford: Berg, 2006); Mark Hailwood \& Deborah Toner, eds., Biographies of Drink: A Case Study Approach to Our Historical Relationship with Alcohol (Newcastle: Cambridge Scholars Publishing, 2015).

3 On drinking and drunkenness as social problems in relation to industrialisation and urbanisation, see, for example, Brian Harrison, Drink and the Victorians: The Temperance Question in England, 1815-1872 (London: Faber \& Faber, 1971); Laura L. Phillips, Bolsheviks and the Bottle: Drink and Worker Culture in St Petersburg, 1900-1929 (DeKalb, Ill.: Northern Illinois University Press, 2000).

4 See, for example, J. Greenaway Drink and British Politics since 1830: A Study in Policy-Making (Basingstoke: Palgrave, 2003); Ian Tyrell Woman's World / Woman's Empire: The Woman's Christian Temperance Union in International Perspective (Chapel Hill: University of North Carolina Press, 1991).
}

(c) The Author(s), 2020. Published by Cambridge University Press 
Recently, historians have recognised more fully the diversity of social and cultural meanings ascribed to alcohol, moving beyond a focus on the social problems to illuminate the ways in which drinking practices and cultures were imbued with significance by participants and commentators alike. ${ }^{5}$ Alongside literature drawn from sociology and cultural studies, anthropological approaches to alcohol have been a particular source of inspiration for historians working to reveal more fully the experiences and discourses (both real and imagined) linked to alcohol production and consumption. ${ }^{6}$ Here, Mary Douglas's work on 'constructive drinking' has helped challenge older preoccupations with social problems linked to alcohol and inspired historians to uncover the positive associations linked to drinking cultures, including the forging of social bonds within communities. ${ }^{7}$ By interrogating the diverse and sometimes contested meanings ascribed to alcohol across different social and cultural settings, scholars have shown the usefulness of alcohol as a frame through which to examine societal structures and cultural developments among communities and groups ranging from the familial and generational to the local, regional, national and transnational.

\section{Wine and Space}

This special issue examines the place of alcohol in and across a series of national, transnational, supranational, and sub-national - local and regional - contexts in twentieth-century Europe. The focus of the articles is particularly on wine and the scale mostly frequently explored in the articles is that of the 'nation', but we are interested also in examining the connections between wine production and consumption with that of other types of alcoholic beverage as well as how national dimensions of these processes and discourses intersected with policies, processes and discourses produced at scales both larger and smaller than that of the nation.

Our focus on wine is significant. A complex and culturally freighted commodity, wine's production, consumption, regulation and imagination across twentieth-century Europe interconnects with multiple converging and competing histories. Well-established as a focus for popular histories, scholarly interest in wine is growing, with particular interest in globalisation an important recent development. ${ }^{8}$ Our focus on wine also opens up analytical directions. Building on older histories of traditional practices in countries like France, ${ }^{9}$ which have led European viti-viniculture over hundreds of years, we consider hitherto neglected histories of the development and regulation of wine production and consumption in different political structures and regimes and in several comparatively under-explored settings, including Bulgaria and the United Kingdom.

The spatial framing of our special issue operates in two ways. Firstly, drawing on a wide range of subjects and case studies from twentieth-century Europe, this collection contributes to scholarly interest in drinking spaces. Influenced by the broader multi- and inter-disciplinary 'spatial turn', in recent years historians have explored the social and cultural setting of drinking spaces - that is those venues and sites where alcohol is consumed - in order to reveal more fully the practices and meanings linked

5 This is the approach taken in Mark Hailwood and Deborah Toner, eds., Biographies of Drink, and also in the special issue of Past and Present devoted to 'cultures of intoxication', Phil Withington and Angela McShane eds., vol 222, supplement 9, 2014.

6 Mark Hailwood, 'Historical Perspectives', in Torsten Kolind, Betsy Thom and Geoffrey Hunt, eds., The Sage Handbook of Drug and Alcohol Studies: Social Science Approaches (London: Sage, 2016), 9-26.

7 Mary Douglas, ed., Constructive Drinking: Perspectives on Drink from Anthropology (Cambridge: Cambridge University Press, 1987).

8 Kolleen M. Guy, When Champagne Became French: Wine and the Making of a National Identity (Baltimore \& London: The Johns Hopkins University Press, 2003); Charles Ludington, The Politics of Wine in Britain: A New Cultural History (Basingstoke: Palgrave Macmillan 2013); Andrew W. M. Smith, Terror and Terroir: The Winegrowers of the Languedoc and Modern France (Manchester: Manchester University Press, 2016); Kym Anderson and Vicente Pinilla, ed., Wine Globalization: A New Comparative History (Cambridge: Cambridge University Press, 2018).

9 Thomas Brennan, 'Towards the Cultural History of Alcohol in France'; Kolleen M. Guy When Champagne Became French; Marion Demossier, Wine Drinking Culture in France: A National Myth or a Modern Passion? (Cardiff: University of Wales Press, 2010). 
to alcohol consumption, with attention paid to the architecture, design and material culture of drinking sites and their use by, and impact on, drinkers. ${ }^{10}$ Interest in drinking spaces has focused primarily on commercialised venues including bars, taverns and pubs, and has offered important avenues for the exploration of working-class leisure, helping uncover the history of everyday popular culture. Adding further depth to this scholarship, this collection also explores consumption practices in domestic settings and among more affluent drinkers, thereby generating a fuller account of the meanings ascribed to alcohol and its spaces of consumption in the last century. Brian Griffith, for example, charts the efforts of what he terms Italy's 'Industrial Wine Lobby', in consort with the fascist government during the 1920s and 1930s, to modernise and sanitise the traditional spaces in which alcohol, especially wine, was consumed in Italy - bettole and osterie - as part of their drive to make the consumption of Italian wines more palatable to middle class consumers. Stella Moss, in her article, demonstrates how continental package holidays, supermarket stocklists and labelling and pedagogical literature - in the shape of wine guides and Good Housekeeping magazine - came together to allow British domestic consumers of wine, particularly women, to deploy wine as a 'positional good' in their homes, a shorthand to signify their own status as cosmopolitan and knowledgeable, and as a marker of socio-economic esteem.

Secondly, the special issue takes a spatial frame to the subject of alcohol and its relationship with identities, practices and articulations of power insofar as the articles presented here consciously explore the intersections of alcohol and identity, practice and power at, across and between different scales of analysis and experience. ${ }^{11}$ Producing, procuring, distributing and consuming alcohol were activities in twentieth-century Europe that in some way brought the individuals involved into contact with the state, and most often, though not always, the nation state. Within this relationship, the state predominantly acted to regulate and discipline alcohol production and consumption, but also at times to facilitate these, at least with respect to certain types of alcoholic drinks, often those considered to have national, religious or cultural significance. In this volume, we see state led and sanctioned efforts to (re)establish wine as a 'national drink' in Alsace, returned to French rule in 1918, in fascist Italy, and in communist Bulgaria. For their part, whilst individual producers and consumers were often compelled to comply with state exigencies around alcohol, they could also act to skirt or subvert state diktats, as was the case with the Regional Committee for Viticultural Action (Comité Régional d'Action Viticole; CRAV) wine-producers documented by Andrew Smith, or at times themselves acted to engage the state, and enjoin it to intervene in questions of alcohol production and consumption. In Maria Chen's article, we are introduced to a case in which a nation entreats a supra-national entity to intervene in regulating wine production in order, at least in part, to reduce, or redirect the wrath of local producers.

Still, whilst the modern nation state has played a critical role in shaping processes, practices and identities around alcohol, it is crucial to recognise that in doing so, states interacted with individual actors, societies and associations, and institutions that operate at scales both bigger and smaller than that of the nation state. It is also vital to acknowledge that interactions and 'relations of power' involving alcohol also operated at scales other than that of the state/nation, and, moreover, that the state/nation was not always and in all places the dominant unit of power or experience in

10 Madelon Powers, Faces Along the Bar: Lore and Order in the Workingman's Saloon, 1870-1920 (Chicago: University of Chicago Press, 1998); Kevin Kearns Dublin Pub Life and Lore: An Oral History (Dublin: Gill and Macmillan Ltd. 1997); Claire Langhamer, "'A Public House is for All Classes, Men and Women Alike”: Women, Leisure and Drink in Second World War England', Women's History Review, 12, 3 (2003), 423-3; W. Scott Haine, The World of the Paris Café: Sociability Among the French Working Class, 1789-1914 (Baltimore, MD: Johns Hopkins University Press, 1996); Robert Duncan, Pubs and Patriots: The Drink Crisis in Britain During World War One (Liverpool: Liverpool University Press, 2013); Anthony Cooke, A History of Drinking: The Scottish Pub Since 1700 (Edinburgh: Edinburgh University Press, 2015); Stella Moss 'Manly Drinkers: Masculinity and Material Culture in the Interwar Public House', in Hannah Greig, Jane Hamlett and Leonie Hannan, eds., Gender and Material Culture in Britain Since 1600 (London: Palgrave, 2015).

11 Bernard Struck, Kate Ferris and Jacques Revel, 'Introduction: Space and Scale in Transnational History', in The International History Review, special issue: 'Size Matters: Scales and Spaces in Transnational and Comparative History', 33, 4 (2011), 573-84. 
these exchanges and formations. Wine's production, consumption and regulation traversed national borders and in doing so reveals different forms of European identities which in turn intersected with factors including class, gender and race. Wine regulation could be the source of intense and complex local, regional, national and transnational contestation. With this collection, we hope to open up new ground in thinking about transnational comparisons of the politics of drink in general, and wine in particular. This is seen most vividly in the influence of the European Economic Community (EEC) and the European Union (EU) in regulating wine production and consumption, explored from very different perspectives by both Chen and Smith in this issue. In stark contrast with historic norms of viti-viniculture, which underlined the importance of the local and regional in production and consumption practices, the twentieth century saw an expansion of the geographic scales of influence across national boundaries and in some cases across the continent - forces which in turn both shaped and reflected the globalising forces at work in the wine trade.

Several of the articles in this collection examine the articulation of power, identity and practices around alcohol production, distribution and consumption at scales both smaller (Languedoc-Roussilon; Alsace) and larger (the European Economic Community; British tourists' wine consumption in southern Europe) than that of the nation. Many of these analyses consciously move between local, national and/or transnational scales and find significance precisely in the interrogation of the dynamics between, for example, local producers and individual consumers, national authorities and bodies, and multi-national corporations and supra-national institutions. Alison Carrol's article in this collection takes a contested border region, Alsace, to examine how wine (and beer) were co-opted as agents and emblems in renegotiating political and national allegiances and identities between France and Germany in the aftermath of its return to French rule following the First World War. In Andrew Smith's study the embattled Languedoc wine growers grouped in the CRAV brought to bear regional identity, memories of decolonisation and far-right politics in their violent resistant actions that identified, variously, multi-national supermarket chains, the French Republic and the EEC as threats to their livelihood and ways of life.

\section{Identity; Practice; Power}

The following studies of alcohol in twentieth-century Europe raise important points on three interconnected themes: identity, practice and power. First and foremost, the collection considers the role of alcohol and wine in particular in the cultivation, expression and contestation of identity. With reference to diverse geographic and temporal contexts, the collection illuminates the varied influence of factors including (but not limited to) class, gender, race, ethnicity, age, sexuality and local, regional and national identities in shaping the identities of wine producers and consumers. ${ }^{12}$ Social practices and cultural norms governing behaviours and rituals around wine (and alcohol more broadly) could vary significantly according to different facets of identity, and in relation to both individual and collective experience. Across different scales, from local, everyday drinking rituals to wine related political discourse at national and transnational levels, the interlinking of identity with attitudes towards, and experiences of, wine was ever present, though often shifting in form as the articles in this collection reveal.

Practice is the second major theme emerging from this collection of articles. Twentieth-century Europe witnessed a range of different wine related practices, spanning production, consumption and regulation: the growing practice of mixed sex drinking in public spaces of alcohol consumption and the transition to increased wine consumption in domestic and commercial settings among northern European populations, more readily associated with beer consumption, are cases in point, the latter explored by Stella Moss in a UK context in this volume. ${ }^{13}$ Diverse communities and social

12 For examples of other studies engaged with exploring the intersection of alcohol and identity formation and fashioning, see Deborah Toner's Alcohol and Nationhood in Nineteenth-century Mexico (Lincoln, NE: University of Nebraska, 2015); David Carey Jr., Distilling the Influence of Alcohol: Aguardiente in Guatemalan History (Gainesville: University of Florida Press, 2012).

13 For examples of other studies exploring mixed sex drinking, see Stella Moss, “A Harmonizing Whole”: Music, Mass Observation and the Interwar Public House', in W. Osgerby, Subcultures, Popular Music and Social Change 
networks performed wine related behaviours which generated meaning across a range of contexts, from everyday popular recreation to the arena of high politics. Consideration of spaces and places linked to wine - vineyards, bars, taverns, homes and other sites of production and consumption reveals more fully different kinds of wine related practice, such as drinking rituals or worker protests imbued with particular meaning and symbolism according to location, time and participant. The collection considers the ways in which historical actors were enmeshed in different kinds of practice, both real and imagined, where the performance of wine related behaviours and rituals was both constitutive and reflective of broader societal structures and developments. In post-Stalinist Bulgaria, for example, both wine drinking, especially of homemade wine, as well as abstaining from drinking alcohol, offered routes to perform 'socialist progress'; in 1970s Britain, the enactment of a kind of 'middlebrow' wine connoisseurship among the middle-class, heterosexual, married readership of Good Housekeeping magazine, both shaped and was shaped by expanding leisure cultures inside and outside the home. Discussion of practice also reveals the importance placed on authenticity in relation to the making and drinking of wine: upholding and transgressing traditions of production and consumption could connote wider meaning, reflecting, for example, regional and national discourses about socially acceptable popular culture or the performance of rituals designed to publicly signal the expression of good taste.

It is worth observing here that abstinent and temperant practices are not a predominant focus for the articles in this special issue - although these are addressed both in Mary Neuburger's article on communist Bulgaria and Brian J. Griffith's article on fascist Italy - in part because societal activism, discourses and practices around prohibition, abstinence and temperance were among the earliest subjects to be investigated by historians interested in alcohol. ${ }^{14}$ It is also the case, we acknowledge, that the colonial dimensions of wine production and consumption that were integral to a number of countries and communities under discussion in this volume are not addressed, with the exception of Andrew Smith's article, which recognises the impact of the 'afterlives' of the Algerian War in Languedoc wine growers' interactions with the French state and the EEC. Whilst our focus in this issue has been to engage with local, national and transnational contexts of wine production and consumption within Europe, we'd point to the excellent recent work by Elizabeth Heath and Owen White, among others, on the place of wine in the 'economics of empire' between France and Algeria. ${ }^{15}$

The third major theme is power. The collection reveals the complex relationship between alcohol and power across the twentieth century, linking nations and states, different forms of political authority, regulatory bodies and diverse communities and groups of citizens. Wine is understood to have operated on different axes of power, including both the vertical and the horizontal. The regulation of wine quality, for instance, has long shaped power relations at a macro-level, as Chen demonstrates in relation to the EEC and EU policies. The recognition and appreciation of quality wine could also exert notable authority across and within communities of drinkers, as Carrol considers in terms of Alsace and Moss in connection with Britain. Alcohol also acted as a commodity through which citizens could be mobilised, rewarded and controlled in different ways. And wine could also offer ordinary

(Newcastle: Cambridge Scholars Publishing, 2014), 105-20; and Claire Langhamer, “'A Public House Is For All Classes”, 423-43.

14 Brian Harrison, Drink and the Victorians; Patricia E. Prestwich, Drink and the Politics of Social Reform: Antialcoholism in France Since 1870 (Palo Alto, CA: Society for the Promotion of Science and Scholarship, 1988); Ian Tyrell, Woman's World / Woman's Empire; Joseph Bohling, The Sober Revolution: Appellation Wine and the Transformation of France (Ithaca, NY: Cornell University Press, 2018).

15 Elizabeth Heath, Wine, Sugar, and the Making of Modern France: Global Economic Crisis and the Racialization of French Citizenship, 1870-1910 (Cambridge: Cambridge University Press, 2014); 'Economics of Empire: Wine, France, and Algeria', special issue of French Politics, Culture \& Society, 35, 2, (2017), including Elizabeth Heath 'The Color of French Wine: Southern Wine Producers Respond to Competition From the Algerian Wine Industry in the Early Third Republic', 89-110; and Owen White, 'Roll out the Barrel: French and Algerian Ports and the Birth of the Wine Tanker', 111-32; Andrew W.M. Smith, Terror and Terroir: The Winegrowers of the Languedoc and Modern France (Manchester: Manchester University Press, 2016), 75-9, 91-8; John Strachan, 'The Colonial Identity of Wine: The Leakey Affair and the Franco- Algerian Order of Things', Social History of Alcohol and Drugs, 21, 2 (2007), 118-37. 
citizens a product through which they might resist or transgress authority and regulation or broader social and cultural norms regarding issues such as class, gender and race. ${ }^{16}$ Among particular communities, the performances of wine related rituals could be seen as a way to claim, subvert or reject authority, both individually and collectively. Here levels of consumption and attitudes towards drunkenness might sway marked influence, creating fault lines according to perceptions of social acceptability, in that what for one social group might be a night of drunken barbarism might for others be light-hearted ritual of social levity. Access to particular kinds of wine could engender important kinds of soft power in the context of community sociability, including, for example, the consumption of high-quality varieties as a marker of social distinction.

\section{Concluding Remarks}

The temporal range of the articles in this issue spans from the 1920s to the 1980s, a period which is so often defined by its major conflicts and transformations from the world wars and the Cold War to decolonisation and social revolutions. The articles explore alcohol related policies, practices and identities across both the democratic and illiberal regimes that governed in this period. This span allows us to make some tentative comparative observations about the contribution of alcohol to articulations of identity and power and the enactment of practices across territories governed by different political systems and ideologies: democratic, communist and fascist. Given that drinking is closely tied to the assertion, regulation and challenging of power - for example through the policing of the availability of alcohol, or certain types of alcoholic drinks, to particular societal groups - it is of course the case that drinking practices and drinking cultures in twentieth-century Europe have been conditioned by the political systems and ideologies that governed the societies in which they were formed and effected. As both Griffith and Neuburger demonstrate, for example, wine producers and regime officials were very often quick to seek to align wine not just with an all-embracing ideal of the 'national drink' but to connect it specifically with the political goals and concerns of fascism and communism, whether autarky or the socialist 'good life'. Similarly, Carrol's article explicates how wine was identified by the French Third Republic and Alsatian local government officials as central to 'reversing Germanisation' and to (re-)cementing French rule in the region.

As this collection underlines, though, alcohol as a 'global commodity' is also thoroughly 'transpolitical'. Its attendant cultures, practices, spaces, policies, associational activity and so on, are deeply - perhaps inherently - politically ambivalent and flexible. British holidaymakers and consumers at home drank wines produced in vineyards and by workers governed by authoritarian regimes. There is no singularly democratic or dictatorial approach to alcohol in society. For example, whilst prohibition might be considered, by definition, an 'illiberal policy', it is one that tends to be associated as much, if not more (certainly in popular perceptions), with the historical liberal democratic states - the United States, Canada and Norway, for example - than with the illiberal regimes that pursued it, such as Russia/the Soviet Union and the Hungarian Soviet Republic. ${ }^{17}$ Just as prohibitionist or highly regulatory policies on alcohol production and consumption were not the preserve of illiberal - or democratic - regimes alone, the expansion and facilitation of opportunities to produce and consume alcoholic drinks was not reserved solely for citizens in democratic, capitalist Europe. Meanwhile and conversely, the fascist regimes in Germany and Italy, whilst showing some adherence to and/or sympathy with anti-alcohol ideals, enacted policies that actively encouraged the consumption of some - national - alcoholic drinks, aligning this with broader values of nationalism, autarky and the eulogising of artisanal and rural agricultural ways of life, as attested in the work of Sina Fabian on Nazi Germany and by Kate Ferris and (in

16 See, for example, Emily Remus, 'Tippling Ladies and the Making of Consumer Culture: Gender and Public Space in Fin-de-Siècle Chicago', Journal of American History, 101, 3 (2014), 751-77; Kate Ferris, 'Women and Alcohol Consumption in Fascist Italy', (forthcoming).

17 Mark Lawrence Schrad, The Political Power of Bad Ideas: Networks, Institutions and the Global Prohibition Wave (Oxford: Oxford University Press, 2010). 
this volume) by Brian Griffith on fascist Italy. ${ }^{18}$ There are notable similarities in the ways in which the fascist government in Italy and the Soviet-backed communist government in Bulgaria used wine as an agent and symbol for binding supposed millennia-old national tradition to contemporary political projects. Taken collectively, the articles here counsel caution not to overstate major divergences in terms of alcohol related policy, attitudes and practices solely on the basis of the democratic or dictatorial credentials and political ideologies of the states concerned.

What follows are six articles setting out some of the latest thinking on the place of alcohol in histories of identity formation and the articulation and enactment of practices and power in twentiethcentury Europe. The article authors and special issue editors enter into dialogue with present and past scholarship on the history of alcohol and alcohol in history and hope to contribute to the on-going development of these scholarly conversations. Taken together, to paraphrase Brennan, they show that there is a great deal to learn about twentieth-century European societal, cultural, economic and political transformations through a wine glass: how efforts to regulate viticulture and wine production in interwar and post-war Europe were crucial opportunities to negotiate political authority between national, local and supranational actors, whether to re-assert the Frenchness of Alsace, or to build - or resist - a European Common Wine Policy; how the social and cultural practices of everyday wine consumption were occasions for individual and collective identity fashioning and meaning-making not only in the southern European producer countries with which it was most readily associated, but also - increasingly and in ways that intersected heavily with class, gender and other markers - in places where it was not made (or where the illusion that it was not made held political significance, as in the case of Germanic Alsace) but was consumed; how strikingly similar discourses and policies around anti-alcoholism or, conversely, around wine as a 'national drink' and discourses and practices around gendered drinking, notably women's drinking, were present across countries with (in theory) profoundly divergent political regimes.

The articles are not grouped into sub-themes but simply appear in order of their chronological starting point; as editors we have consciously chosen to eschew distinguishing articles according to different foci on producers and production, regulation and consumption precisely because the collection as a whole, and individual articles in particular, lay out important overlaps, interactions and interrelations between producers, regulators and consumers of alcohol. As editors and readers of these articles, we discern some interesting symbioses and points of connections between the articles: questions of agency and the articulation of power at and between local and supra-national scales in Chen and Smith's articles; the call to contemporary and historic (indeed, ancient) imaginaries of alcohol across diametrically opposed (and diachronic) political regimes explored by both Griffith and Neuburger; the 'meaning-making' connected to gender, class and national belonging, attached to alcohol related practices, evident in Carrol and Moss's articles. That said, we hope and anticipate other readers will identify different linkages between the histories explored in the articles in this special issue; in inviting readers of this collection to consider the themes and connections that we have explicitly laid out - the place of alcohol in articulations of identity, power and practice across and between different scales of experience and analysis - as well as to make links of their own among the articles here presented, and between them and wider scholarship, we hope to encourage and to participate in the continuing expansion and stimulation of this lively and instructive field.

\footnotetext{
18 Sina Fabian 'Wine, Festivals and "Volksgemeinschaft", unpublished paper given at the 'Drink and Power: Alcohol and the Making of Illiberal Regimes in the long $20^{\text {th }}$ century', Forum Transregionale Studien, Berlin, Mar. 2019; Kate Ferris 'Women and Alcohol Consumption in Fascist Italy' (forthcoming).
}

Cite this article: Ferris K, Moss S (2020). Alcohol Production and Consumption in Contemporary Europe: Identity, Practice and Power Through Wine. Contemporary European History 29, 373-379. https://doi.org/10.1017/S0960777320000399 